\title{
Chemical composition of cold pressed Brazilian grape seed oil
}

\author{
Fernanda Branco SHINAGAWA ${ }^{1}$, Fernanda Carvalho de SANTANA $^{1}$, Elias ARAUJO ${ }^{1}$, Eduardo PURGATTO ${ }^{1}$, \\ Jorge MANCINI-FILHO ${ }^{1 *}$
}

\begin{abstract}
Grape seed oil (GSO) is an important by-product of the wine-making industry which has received attention as an alternative source of vegetable oils; its chemical compounds can be influenced by agricultural practices and industrial processing. Knowledge of the composition of Brazilian GSO is scarce; thus, this study aimed to analyze the chemical characteristics, as well as the antioxidant activity of these oils. GSO samples were obtained from Brazilian markets and showed significantly high amounts of phenolic, $\gamma$-tocotrienol and phytosterols as well as, the presence of several volatile compounds. Based on these results, is possible to show that oils exhibited good antioxidant activity. Therefore, it can be inferred that Brazilian GSO had a considerable content of phytochemical compounds with biological activity, which allows its association with other vegetable oils.
\end{abstract}

Keywords: seed oils; micronutrients; antioxidant activity.

Practical Application: In this study Brazilian grape seed oils were found to have potential to be used for some industrial sectors, such as food ingredients and cosmetics industry. They showed high amount of polyunsaturated fatty acid and significant amount of vitamin E, phenolics, phytosterols and volatile compounds. The knowledge regarding the composition of the products is important once they are made from a sustainable way.

\section{Introduction}

Recent data from the Food and Agriculture Organization of the United Nations (2014) shows that Brazil is the eleventh highest grape producer in the world and its harvest corresponds to approximately 1.5 million tons of grapes (Instituto Brasileiro de Geografia e Estatística, 2012). The Rio Grande do Sul state remains notable as the largest national producer, with 829.589 tons of production per year, representing approximately $55 \%$ of Brazil's total cultivation within an increase of the wine sector nationwide.

There is a worldwide trend to seek new sources of vegetable oil, and a wide range of research has been conducted to identify new oils from fruit, and especially fruit seeds (Madawala et al., 2012). In this context, cold pressed grape seed oil is an environmentally suitable vegetable oil as it is a value added by-product of wine and grape juice-making process.

Lipid content in grape seed is around $7-20 \%$. The importance of grape seed use is mainly due to the fact that it is rich in lipids and bioactive compounds, such as vitamin E, phytosterol and phenolic compounds, among other components with biological activity, which are important for food, pharmaceutical and cosmetic industries (Kim et al., 2013; Rockenbach et al., 2010; Nakamura et al., 2003).

Motivated by the lack of information on the chemical data of grape seed oil (GSO) produced in the world and mainly by the absence of information for Brazilian oils, the aim of this study was to analyze the chemical composition of Brazilian GSO in order to expand the knowledge of its characteristics and infer its potential for human health.

\section{Material and methods}

\subsection{Reagents and standards}

All solvents were analytical grade, used within their expiration dates and purchased from Merck (Darmstadt, Germany). The hexane and isopropanol used in this study were high performance liquid chromatography (HPLC) grade. Furthermore, the boron trifluoride-methanol solution $14 \%\left(\mathrm{BF}_{3} 14 \%\right)$, fatty acid methyl ester (FAME) mix (C4:0-C24:0), methyl tridecanoate (C13:0), tocopherols ( $\alpha$-tocopherol, $\beta$-tocopherol, $\gamma$-tocopherol, $\delta$-tocopherol), $\delta$-tocotrienol, campesterol, stigmasterol, sitosterol, 5 - $\alpha$-cholestane and $\beta$-carotene (type II, synthetic) were obtained from Sigma-Aldrich (St. Louis, MO, USA).

\subsection{Oil samples}

GSO was obtained from Brazilian markets between July 2012 and August 2013. The cold pressed samples were identified as follows: UVB (Antônio Prado, RS, Brazil), URS (Bento Gonçalves, RS, Brazil), OOV (Guaribalde, RS, Brazil) and CAC (Estância Velha, RS, Brazil). After receiving the samples at the Lipids Laboratory (Faculty of Pharmaceutical Science, University of São Paulo, São Paulo, Brazil), they were fractionated into amber glass bottles, nitrogen gas was added in the headspace and the samples were maintained at $-20^{\circ} \mathrm{C}$ until further analysis. 


\subsection{Color parameters}

Color parameters were evaluated by colorimeter (ColorQuest XE, Hunter Assoc. Laboratory, Reston, USA), with a field of view of $10^{\circ}$, D65 type illuminant and slit diameter of $1 \mathrm{~mm}$. The following color coordinates were determined in the Cielab system: lightness $\left(\mathrm{L}^{*}\right)$, redness $\left(\mathrm{a}^{*}\right.$, red to green axis) and yellowness $\left(b^{*}\right.$, yellow to blue axis).

\subsection{Fatty acid composition}

Fatty acid methyl esters (FAME) were obtained using $\mathrm{BF}_{3}$ $14 \%$ according to the Ce 2-66 method (American Oil Chemists' Society, 2009). Separation of FAME was performed using a gas chromatograph (Shimadzu Plus 2010, Kyoto, Japan), equipped with a split injector system, an auto-sampler and fused silica capillary column (SP-2560, $100 \mathrm{~m} \times 0.25 \mathrm{~mm} \times 0.2 \mu \mathrm{m})$. The column temperature gradient was programmed between 140 and $220^{\circ} \mathrm{C}$ and detection was performed with a flame ionization detector (FID) at $260^{\circ} \mathrm{C}$. Helium was used as a carrier gas $\left(1 \mathrm{~mL} \mathrm{~min}^{-1}\right)$. FAME were identified by comparing the retention time of the sample peaks with a standard mixture of 37 fatty acid methyl esters, C4:0-C24:0 (Sigma Chemical Co St. Luis, MO, USA). The results were expressed as direct area $\%$ for each peak identified.

\subsection{Phytosterol composition}

Phytosterol determination was followed by Duchateau et al. (2002) with some modifications. Internal standard 5- $\alpha$-colestane (1.0 $\mathrm{mg} \mathrm{mL}^{-1}$ hexane) was added to each sample before saponification (methanolic $\mathrm{KOH} 3 \%$ at $50 \pm 2{ }^{\circ} \mathrm{C}$ for 3 hours). After three extractions with hexane, the organic phase was collected, evaporated and ressuspended in $150 \mu \mathrm{L}$ of hexane before injection into a GC system. A gas chromatograph (Shimadzu Plus GC 2010, Kyoto, Japan) equipped with a FID detector and a fused silica capillary column LM 5 (5\% phenyl $95 \%$ methylpolysiloxane $60 \mathrm{~m} \times 0.25 \mathrm{~mm}$ internal diameter with $0.25 \mu \mathrm{m}$ particle size) was used. The GC program was as follows: column temperature, $290{ }^{\circ} \mathrm{C}$; detector temperature, $300{ }^{\circ} \mathrm{C}$; helium $\left(1 \mathrm{~mL} \mathrm{~min}^{-1}\right)$; and split ratio $1 / 50$. Phytosterols were identified and quantified by comparing the relative retention time of standard campesterol (C5157), stigmasterol (S 6126) and $\beta$-sitosterol (S 9889) (Sigma-Aldrich Co., St. Louis, USA). The results were expressed in $\mathrm{mg} 100 \mathrm{~g}^{-1}$ of oil.

\subsection{Tocopherol/Tocotrienol profile}

$\alpha$-, $\beta$ - and $\gamma$-tocopherol and $\gamma$-tocotrienol levels were determined according to the Ce 8-89 method (American Oil Chemists' Society, 2009). The oil samples were diluted with hexane $\left(0.1 \mathrm{~g} \mathrm{~mL}^{-1}\right)$ and filtered through a $0.22 \mu \mathrm{m}$ PTFE membrane filter. Then, samples were analyzed by an HPLC (Shimadzu CBM-20A, Kyoto, Japan) consisting of an RF-10AXL fluorescence detector (excitation $=295 \mathrm{~nm}$ and emission $=330 \mathrm{~nm})$. A normal silica phase column (Sim-pack CLC-SIL, $250 \times 4.6 \mathrm{~mm}$ internal diameter with $0.5 \mu \mathrm{m}$ particle size) was used with hexane:isopropanol $(99: 1 \mathrm{v} / \mathrm{v})$ as a mobile phase. The system was operated isocratically at a flow rate of $1 \mathrm{~mL} \mathrm{~min}^{-1}$. Identification of synthetic standards tocopherols ( $\alpha, \beta, \gamma$, and $\delta$-tocopherol and $\delta$-tocotrienol) (Sigma Chemical Co St. Louis, MO, USA) was conducted by comparing the HPLC retention time with those of standard compounds under the same operating conditions, and the quantification was based on an external standard method. The results were expressed in $\mathrm{mg} 100 \mathrm{~g}^{-1}$ of oil.

\subsection{Total phenolics}

The phenol extraction was carried out with a methanolic extract obtained according to Bail et al. (2008) and quantification was based on the colorimetric method by Hills \& Swain (1959) using Folin-Ciocalteau adapted to a microplate reader (Biotek', Synergy HT model, Winooski, VT, USA). Absorption was measured at $720 \mathrm{~nm}$. A standard curve was used, with gallic acid ( 0.50 to $\left.5.00 \mathrm{mg} \mathrm{mL}^{-1}\right)$, obtaining a correlation coefficient of 0.9987 . The content of phenolic compounds in the oils was expressed as $\mathrm{mg}$ of gallic acid equivalents per 100 grams of sample (mg GAE $100 \mathrm{~g}^{-1}$ ).

\subsection{Total carotenoids}

Total amounts of carotenoids were determined using Ranjith et al. (2006) following some modifications. GSO were dissolved in hexane $\left(0.1 \mathrm{~g} \mathrm{~mL}^{-1}\right)$, vortexed for $30 \mathrm{~s}$ with $\mathrm{NaCl}$ $0.5 \%$, and centrifuged for $10 \mathrm{~min}$ at $1500 \mathrm{~g}$. Aliquots of $250 \mu \mathrm{L}$ of the upper phase were collected and measured at $460 \mathrm{~nm}$ with a microplate reader. Carotenoid quantification was based on a calibration curve with $\beta$-carotene standard, type II: synthetic (Sigma-Aldrich Co., St. Louis, USA). The results were expressed as $\mathrm{mg}$ of $\beta$-carotene equivalent per one hundred grams of oil (mg bCE $100 \mathrm{~g}^{-1}$ of oil).

\subsection{Total chlorophylls}

Total chlorophyll analysis was performed by MinguezMosquera et al. (1991) based on a dilution of the sample in cyclohexane PA, then read at $670 \mathrm{~nm}$ using spectrophotometric equipment. Quantification was conducted by the following equation: Total Chlorophyll $=\left(\right.$ Absorbance $\left.\times 10^{6}\right) /\left(613 \times 10^{2} \times\right.$ oil density $)$ and the results were expressed as milligrams per kilogram of chlorophyll oil $\left(\mathrm{mg} \mathrm{kg}^{-1}\right)$.

\subsection{Volatile compounds}

Volatile compounds were extracted by headspace solid-phase microextraction and analyzed by gas chromatographic massspectrometric method (HS-SPME-CG/MS). SPME compatible vials containing $1 \mathrm{~g}$ of the each oil were extracted isothermally for $24 \mathrm{~h}$ to produce sufficient amounts of analytes at room temperature $\left(25^{\circ} \mathrm{C}\right)$ and then the headspace was absorbed using a pre-conditioned column (Supelco 57330-U, Melbourne, Australia) for 30 minutes. After sampling had been carried out, the SPME fiber was immediately exposed to the inlet temperature of the GC-MS instrument. For the separation of volatile compounds, a non-polar column $(30 \mathrm{~m} \times 0.25 \mathrm{~mm} \times 0.25)$ (Hewlett-Packard HP-6890 model, HP-5MS, California, USA) equipped with a mass selective detector (Hewlett-Packard HP-5973, California, USA) was used. The column temperature gradient was programmed between 40 and $160{ }^{\circ} \mathrm{C}$ and the injector temperature was $200^{\circ} \mathrm{C}$. After 4 min using the splitless mode of the expurgate GC-MS-system, 
a constant flow of $1 \mathrm{~mL} \mathrm{~min}^{-1}$ was applied, carrying helium. Mass spectra were recorded with a scan range of 10-300 amu. Volatile compound identification was carried out using Wiley 275, NBS $75 \mathrm{~K}$ and in-house mass spectra libraries and partly by the co-injection of reference compounds.

\subsection{Oxidative established index (OEI)}

The oxidative stability index was determined using Rancimat ${ }^{\circledR}$ equipament (model 743, Metrohm Ltd., Herisau, Switzerland) according to the Cd 12b-92 method (American Oil Chemists' Society, 2009). The induction period (IP) of oxidation at a temperature of $120^{\circ} \mathrm{C}$ and oxygen flow $20 \mathrm{~L} \mathrm{~h}^{-1}$ was determined in hours (h).

\subsection{Antioxidant capacity assays}

$\operatorname{ABTS}^{+}$(2,2 'azinobis [3-ethylbenzothiazoline-6-sulfonic acid]) radical scavenging activity was measured according to Re et al. (1999) adapted for a microplate reader. TEAC measurements were achieved by comparing decreased absorption after using $20 \mu \mathrm{L}$ of GSO extract (Bail et al., 2008), reagent blank or Trolox standard, respectively, with $200 \mu \mathrm{L}$ of $7 \mathrm{mM} \mathrm{ABTS}^{+}$. Absorbance was monitored at $734 \mathrm{~nm} 6 \mathrm{~min}$ after the addition of reactant at $25^{\circ} \mathrm{C}$. The TEAC value is expressed as micromolar Trolox equivalents per 100 grams of sample (TE $\mu \mathrm{M} 100 \mathrm{~g}^{-1}$ ).

The ORAC method used was described by Prior et al. (2003) the lipophilic and hydrophilic methods were carried out. For the lipophilic method, samples were diluted in acetone:water $(1: 1)$ with $\beta$-cyclodextrin. For the hydrophilic method, methanolic extract was used according to Bail et al. (2008) and then diluted in ethanol. An automated ORAC assay was carried out on a microplate reader at $493 \mathrm{~nm}$ (filter $485 / 20$ ) and an emission of $515 \mathrm{~nm}$ (filter 528/20). For both methods, fluorescein (40 ๆM) was used and the reaction was performed at $37^{\circ} \mathrm{C}$ the reaction was started by the thermal decomposition of AAPH (2,2' 'azobis [amidinopropane] dihydrochloride) at concentration of $135 \mathrm{mM}$. A Trolox calibration solution was used (6.25-100 $\mu \mathrm{M})$. Fluorescence was measured immediately after addition and measurements were then taken every $5 \mathrm{~min}$ for one hour. ORAC values were expressed as micromolar Trolox equivalents per 100 grams of sample (TE $\left.\mu \mathrm{M} 100 \mathrm{~g}^{-1}\right)$.

\subsection{Statistical analysis}

All analyses were performed in triplicate and results were expressed as mean values \pm standard deviation (SD). The Box-Cox transformation technique was used to normalize non-normal data and significant differences were evaluated using a variance analysis (ANOVA) test followed by a Tukey's Test for significance at the $5 \%$ level $(p<0.05)$. For samples that could not be normalized, the Kruskal Wallis Test was used followed by Dunn's Test $(p<0.05)$. Correlation analyses were performed using Pearson's Test. A multivariate statistical analysis of selected chemical data was performed using principal component analysis (PCA). Statistical analyses were conducted using Prism 5 software (GraphPad, California, USA) and Statistica 7 (Statsoft, Tulsa, Oklahoma, USA).

\section{Results}

\subsection{Fatty acid composition}

Lipid profiles are presented in Table 1; all analyzed samples, without exception, showed higher linoleic acid (C18: 2 n-6) concentrations ranging from 72.19 to $75.02 \%$, followed by monounsaturated oleic acid (C18: $1 n-9)$ between 14.80 to $17.34 \%$, and saturated palmitic acid (C16:0) (9.72 to $10.22 \%)$.

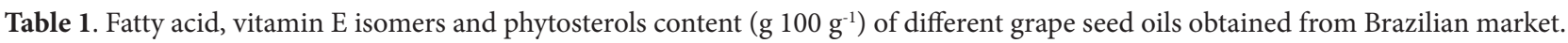

\begin{tabular}{|c|c|c|c|c|}
\hline & OVB & URS & OOV & CAC \\
\hline \multicolumn{5}{|c|}{ Fatty Acid $\left(\mathrm{g} 100 \mathrm{~g}^{-1}\right)$} \\
\hline C16:0 & $6.26 \pm 0.07^{d}$ & $6.52 \pm 0.09^{c}$ & $6.61 \pm 0.02^{b c}$ & $6.70 \pm 0.01^{b}$ \\
\hline C18:0 & $3.42 \pm 0.08^{\mathrm{cd}}$ & $3.36 \pm 0.05^{\mathrm{cd}}$ & $3.22 \pm 0.23^{\mathrm{d}}$ & $3.53 \pm 0.04^{\mathrm{bc}}$ \\
\hline C18:1 $c(n-9)^{\star}$ & $15.83 \pm 0.07^{\mathrm{e}}$ & $17.20 \pm 0.05^{c}$ & $14.80 \pm 0.07^{\mathrm{g}}$ & $15.31 \pm 0.05^{\mathrm{f}}$ \\
\hline C18:2 $c(n-6)^{\star}$ & $74.15 \pm 0.20^{\mathrm{ab}}$ & $72.19 \pm 0.06^{\mathrm{ab}}$ & $75.02 \pm 0.31^{\mathrm{a}}$ & $74.12 \pm 0.11^{\mathrm{ab}}$ \\
\hline C18:3 (n-3) & $0.21 \pm 0.01^{\mathrm{e}}$ & $0.49 \pm 0.03^{\mathrm{a}}$ & $0.36 \pm 0.03^{\mathrm{bcd}}$ & $0.34 \pm 0.01^{\mathrm{d}}$ \\
\hline$\Sigma \mathrm{SFA}$ & $9.72 \pm 0.14^{\mathrm{d}}$ & $9.99 \pm 0.04^{\mathrm{cd}}$ & $9.83 \pm 0.22^{\mathrm{d}}$ & $10.22 \pm 0.05^{\mathrm{bc}}$ \\
\hline$\Sigma$ MUFA & $15.92 \pm 0.07^{e}$ & $17.34 \pm 0.05^{c}$ & $14.80 \pm 0.07^{\mathrm{g}}$ & $15.31 \pm 0.05^{\mathrm{f}}$ \\
\hline$\Sigma \mathrm{PUFA}^{*}$ & $74.36 \pm 0.20^{\mathrm{ab}}$ & $72.67 \pm 0.05^{\mathrm{ab}}$ & $75.38 \pm 0.29^{\mathrm{a}}$ & $74.47 \pm 0.11^{\mathrm{ab}}$ \\
\hline \multicolumn{5}{|c|}{ Vitamin E isomers $\left(\mathrm{mg} 100 \mathrm{~g}^{-1}\right)$} \\
\hline$a-T$ & $1.76 \pm 0.01^{\mathrm{d}}$ & $1.69 \pm 0.02^{\mathrm{e}}$ & $1.33 \pm 0.02^{\mathrm{f}}$ & $1.34 \pm 0.01^{\mathrm{f}}$ \\
\hline$\gamma-\mathrm{T}$ & $0.49 \pm 0.02^{c}$ & $0.61 \pm 0.02^{c}$ & $0.51 \pm 0.03^{c}$ & $0.47 \pm 0.01^{\mathrm{c}}$ \\
\hline$\gamma-\mathrm{T} 3$ & $450.99 \pm 10.34^{\mathrm{a}}$ & $432.50 \pm 14.47^{\mathrm{ab}}$ & $453.48 \pm 4.79^{\mathrm{a}}$ & $417.03 \pm 12.70^{\mathrm{b}}$ \\
\hline \multicolumn{5}{|c|}{ Phytosterols ( $\left.\mathrm{mg} 100 \mathrm{~g}^{-1}\right)$} \\
\hline Campesterol & $12.78 \pm 0.34^{\mathrm{b}}$ & $13.79 \pm 0.07^{\mathrm{a}}$ & $12.90 \pm 0.31^{\mathrm{b}}$ & $13.51 \pm 0.10^{\mathrm{ab}}$ \\
\hline Stigmasterol & $31.98 \pm 5.28^{\mathrm{a}}$ & $32.63 \pm 0.74^{\mathrm{a}}$ & $30.66 \pm 0.32^{\mathrm{a}}$ & $30.57 \pm 0.19^{\mathrm{a}}$ \\
\hline$\beta$-sitosterol & $83.50 \pm 1.28^{\mathrm{a}}$ & $88.86 \pm 1.14^{\mathrm{a}}$ & $84.17 \pm 1.47^{\mathrm{a}}$ & $91.94 \pm 0.32^{\mathrm{a}}$ \\
\hline
\end{tabular}

Data are mean \pm SD $(n=3)$. Means with different letter in a line are statistically significant at $5 \%$ level probability by Tukey Test. ${ }^{\star}$ Non-parametric data were obtained from Kruskal-Wallis Test. Data n.d. (non-detectable). $\Sigma$ SFA = sum of saturated fatty acids; $\Sigma$ MUFA = sum of monounsaturated fatty acids; $\Sigma$ PUFA = sum of polyunsaturated fatty acids. $\alpha$-T: $\alpha$ tocopherol; $\gamma$-T: $\gamma$ tocopherol; $\gamma$-T3: $\gamma$ tocotrienol. 


\subsection{Phytosterol content}

Campesterol, stigmasterol and $\beta$-sitosterol concentrations ranged

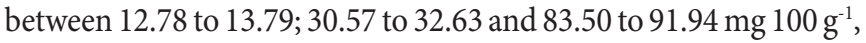
respectively (Table 1 ).

\subsection{Tocopherols and Tocotrienol contents}

Quantification of the tocopherol isomers ( $\alpha$ - and $\gamma-)$ and $\gamma$-tocotrienol were conducted (Table 1). Low values were found when the a-tocopherol isomer was quantified, ranging

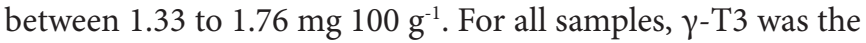
main isomer. Samples submitted to cold pressing showed levels between 417.03 and $453.48 \mathrm{mg} 100 \mathrm{~g}^{-1}$ of $\gamma$-T3 and only the CAC sample differed significantly from the others.

\subsection{Volatile compounds}

Twenty five volatile compounds were identified: six alcohols, four aldehydes, three carboxylic acids, four esters, three hydrocarbons, two ketones and two terpenes (Table 2). Alcohol compounds were more prevalent (\%) for all analyzed samples.

\subsection{Total phenolic, carotenoid and chlorophyll compounds}

Total phenolic quantification showed a range from

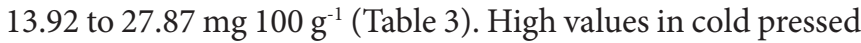

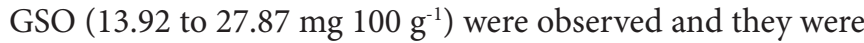
statistically similar $(p<0.001)$.

Total carotenoids and chlorophyll, were also measured (33.85 to $59.85 \mathrm{mg} \mathrm{bCE} 100 \mathrm{~g}^{-1}$ and 0.30 to $0.40 \mathrm{mg} 100 \mathrm{~g}^{-1}$, respectively) (Table 3 ). For both pigments, the URS sample showed a significantly higher value than other samples (both cases, $p<0.001)$. Carotenoid contents in oils is important, for instance, as they provide color (strong correlation with component $\mathrm{b}^{*}$; $r=0.737, p<0.05)$ and have a relation the function of vitamin $A$ precursors (fat-soluble vitamin important to human metabolism).

\subsection{Color parameters}

Samples showed low luminance $\left(\mathrm{L}^{*}\right)$, indicating high turbidity, which ranged from 4.58 to 16.2 ; UVB was the clearest $(p<0.001)$ sample, while the URS stood out as the most turbid. Positive value for the component $b^{\star}$ was

Table 2. Volatiles compounds identification of different grape seed oil from Brazilian market based by HS-SPME-CG/MS.

\begin{tabular}{|c|c|c|c|c|c|c|}
\hline Compounds & CAS number & Odor description & UVB & URS & OOV & $\mathrm{CAC}$ \\
\hline \multicolumn{7}{|l|}{ Alcohol } \\
\hline Ethyl alcohol & [64-17-5] & Floral & & + & + & \\
\hline Isoamilic & {$[123-51-3]$} & Fruity & + & + & + & + \\
\hline Hexanol & {$[111-27-3]$} & Citrus, eucalyptus & + & + & + & + \\
\hline n-Pentanol & {$[71-41-0]$} & Fruity, banana-like & & + & & + \\
\hline 1-octen-3-ol & {$[3391-86-4]$} & Mushroom, fruity & & + & + & + \\
\hline Phenylethylalcohol & {$[60-12-8]$} & Honey, floral & + & + & + & + \\
\hline \multicolumn{7}{|l|}{ Aldehyde } \\
\hline Isopentanal & [590-86-3] & & + & & & + \\
\hline Pentanal & {$[110-62-3]$} & Fruity & & + & + & + \\
\hline Hexanal & {$[66-25-1]$} & Green grass & + & + & + & + \\
\hline 2-Heptenal & [57266-86-1] & Rancid & & + & + & + \\
\hline \multicolumn{7}{|l|}{ Carboxylic Acids } \\
\hline Acetic acid & [64-19-7] & Vinegar & + & & + & + \\
\hline Isovaleric acid & {$[503-74-2]$} & Sweat smell, rotten & + & + & + & + \\
\hline Hexanoic acid & {$[142-62-1]$} & & & & + & + \\
\hline \multicolumn{7}{|l|}{ Esters } \\
\hline Banana oil & [123-92-2] & Sweet, fruity & + & + & + & + \\
\hline Ethyl hexanoate & {$[123-66-0]$} & Fruity, floral & + & + & + & + \\
\hline Ethanodiol, diacetate & [542-10-9] & & + & & & \\
\hline Ethyl octanoate & [106-23-1] & Fruity, floral & + & + & + & + \\
\hline \multicolumn{7}{|l|}{ Furan Compound } \\
\hline Furfural & [98-01-1] & Almond & & & & + \\
\hline \multicolumn{7}{|l|}{ Hydrocarbon } \\
\hline Hexane & [110-54-3] & & + & & & + \\
\hline Toluene & [108-88-3] & Floral & & + & & + \\
\hline Styrene & {$[100-42-5]$} & Pungent, roasty & & + & + & + \\
\hline \multicolumn{7}{|l|}{ Ketones } \\
\hline Acetoin & [513-86-0] & Buttery & + & + & + & + \\
\hline 2,4-methyl-2-hexanone & {$[105-42-0]$} & Spicy, acetone & & + & + & + \\
\hline \multicolumn{7}{|l|}{ Terpenes } \\
\hline a-Limonene & [5989-54-8] & Fresh citrus, orange-like & & + & + & + \\
\hline 4-Carene & {$[5208-50-4]$} & Sweet, pungent & + & + & + & \\
\hline
\end{tabular}

+ Positive 
Table 3. Phytochemicals and pigments quantification from different grape seed oils obtained from Brazilian market and their antioxidant activity.

\begin{tabular}{|c|c|c|c|c|}
\hline & UVB & URS & OOV & $\mathrm{CAC}$ \\
\hline \multicolumn{5}{|l|}{ Cielab parameters } \\
\hline $\mathrm{L}^{*}$ & $16.23 \pm 0.89^{\mathrm{a}}$ & $4.58 \pm 0.45^{\mathrm{d}}$ & $7.95 \pm 0.36^{c}$ & $7.50 \pm 0.09^{c}$ \\
\hline$a^{*}$ & $-0.28 \pm 0.05^{c}$ & $0.86 \pm 0.22^{\mathrm{bc}}$ & $-1.11 \pm 0.44^{\mathrm{b}}$ & $-1.05 \pm 0.18^{b}$ \\
\hline$b^{*}$ & $10.24 \pm 0.46^{\mathrm{a}}$ & $4.58 \pm 0.70^{\mathrm{cd}}$ & $8.40 \pm 0.74^{\mathrm{b}}$ & $8.22 \pm 0.18^{\mathrm{b}}$ \\
\hline \multicolumn{5}{|c|}{ Total Minorities (mg $100 \mathrm{~g}-1$ ) } \\
\hline Phenolics & $27.87 \pm 3.69^{\mathrm{a}}$ & $13.92 \pm 3.60^{\mathrm{b}}$ & $18.21 \pm 1.56^{\mathrm{b}}$ & $16.22 \pm 0.56^{\mathrm{b}}$ \\
\hline Carotenoids & $51.67 \pm 2.08^{\mathrm{b}}$ & $59.85 \pm 3.06^{\mathrm{a}}$ & $33.94 \pm 4.93^{c}$ & $33.85 \pm 4.16^{c}$ \\
\hline Chlorophylls & $0.35 \pm 0.09^{\mathrm{b}}$ & $0.40 \pm 0.05^{\mathrm{a}}$ & $0.30 \pm 0.03^{c}$ & $0.36 \pm 0.14^{\mathrm{b}}$ \\
\hline \multicolumn{5}{|c|}{ Oxidative Stability Index $(h)$} \\
\hline Induction Time & $3.09 \pm 0.55^{\mathrm{a}}$ & $2.94 \pm 0.26^{\mathrm{ab}}$ & $2.36 \pm 0.18^{\mathrm{bc}}$ & $1.37 \pm 0.09^{\mathrm{d}}$ \\
\hline \multicolumn{5}{|c|}{ Antioxidant Activity ( $\mu$ M TE $100 \mathrm{~g}$-1) } \\
\hline ORAC lipophilic & $224.00 \pm 22.28^{c}$ & $432.10 \pm 17.75^{\mathrm{a}}$ & $362.92 \pm 29.75^{b}$ & $370.32 \pm 4.20^{\mathrm{b}}$ \\
\hline ORAC hidrophilic & $625.14 \pm 35.44^{\mathrm{b}}$ & $728.21 \pm 17.01^{\mathrm{a}}$ & $588.84 \pm 5.73^{\mathrm{bc}}$ & $563.83 \pm 14.81^{\circ}$ \\
\hline TEAC & $180.50 \pm 15.82^{\mathrm{a}}$ & $53.41 \pm 3.97^{\mathrm{bc}}$ & $205.52 \pm 9.76^{\mathrm{a}}$ & $192.67 \pm 6.99^{\mathrm{a}}$ \\
\hline
\end{tabular}

Data are mean \pm SD $(n=3)$. Means with different letter in a line are statistically significant at $5 \%$ level probability by Tukey Test. $L^{*}$ : luminosity; $a^{*}$ : green/red; $b^{*}$ : blue/yellow. Oxidative stability index evaluation was compared with soy oil $(3.67 \pm 0.05 \mathrm{~h})$ as a standard in the same conditions. ORAC: Oxygen radical absorbance capacity; TEAC: Trolox equivalent antioxidant capacity.

obtained, with the UVB sample having the highest intensity of yellow (10.24), and the URS sample had the lowest (4.58). Negative values of component $\mathrm{a}^{*}$ were found, ranging from -0.28 to -1.11 (Table 3 ).

\subsection{Oxidative Stability Index (OSI)}

Induction times are showed in Table 3. The degree of unsaturated fatty acids and the presence of minor components in oils are important during the evaluation of the oxidation stability of oils. An average induction time of $2.44 \mathrm{~h}$ was noted. UVB showed statistically higher oxidative stability under the accelerated conditions used in this study $\left(120^{\circ} \mathrm{C}\right.$ for $\left.20 \mathrm{~h} \mathrm{~L}^{-1}\right)$. URS and UVB samples showed higher induction times compared to the others (3.09 and $2.94 \mathrm{~h}$, respectively). In addition, both samples also exhibited higher concentrations of minor components with antioxidant activity, which may have contributed to their increased stability.

\subsection{Antioxidant capacity assays}

The TEAC assay was based on the $\mathrm{ABTS}^{+}$radical scavenging. A range from 53.41 to $205.52 \mu \mathrm{M}$ TE $100 \mathrm{~g} \mathrm{~g}^{-1}$ activity is shown in Table 3. Cold pressed samples such as OOV and CAC had the highest values of antioxidant activity by this method, with a significant difference $(p<0.001)$ when compared to UVB and URS. The antioxidant activity of Brazilian GSO is indicated in Table 3. The URS sample showed a higher value statistically $\left(432.10 \mu \mathrm{M}\right.$ TE $\left.100 \mathrm{~g}^{-1}\right)$ when compared to the other samples in the lipophilic ORAC methodology. On the other hand, the OOV ( $362.92 \mu \mathrm{M}$ TE $\left.100 \mathrm{~g}^{-1}\right)$ and CAC (370.32 $\left.\mu \mathrm{M} \mathrm{TE} 100 \mathrm{~g}^{-1}\right)$ samples showed statistically lower values compared to the URS sample; however, the results did not differ between them. UVB showed a significantly lower value $\left(224.00 \mu \mathrm{M} \mathrm{TE} 100 \mathrm{~g}^{-1}\right)$. The hydrophilic ORAC assay showed the highest activity for URS (728.21 $\mu \mathrm{M} \mathrm{TE} 100 \mathrm{~g}^{-1}$ ) followed by UVB and OOV (625.14 and $588.84 \mu \mathrm{M}$ TE $100 \mathrm{~g}^{-1}$, respectively).

\section{Discussion}

It is widely known that vegetable oils consumption rather than of solid fats is vital to maintaining normal metabolism, in this context GSO consumption plays an important role in human health once the proportions of fatty acids identified increased in the order of AGS < MUFA < PUFA, within an average of 9.94, 15.84 and $74.22 \%$, respectively; this is in agreement with the ranges recommended by international legislation (from 58 to $78 \%$ of LA, 12 to $28 \%$ oleic acid and 5.5 to $11 \%$ palmitic acid) (Food and Agriculture Organization of the United Nations, 2001) and data reported by Sabir et al. (2012) and Crews et al. (2006). High content of PUFAs such as linoleic acid is highly correlated with functional properties, such as a decrease of human total serum cholesterol and LDL-c (Dhvamani et al., 2014).

Seed oils are not only a source of fatty acid, but also a valuable source of micronutrients, such as sterols, carotenoids and tocols. $\beta$-sitosterol was found to be a major phytosterol compound in Brazilian GSO. No statistically significant result was found

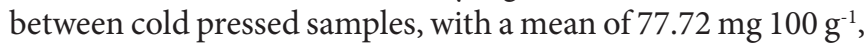
i.e. over $70 \%$ of total phytosterols. This value is in agreement with those found for Rubio et al. (2009). The significant presence of phytosterols in GSO reinforces the potential health benefits of its consumption, since they have a similar chemical structure to cholesterol, so compete for intestinal absorption sites, reducing body cholesterol absorption capacity (Laakso, 2005).

Tocols are the major primary antioxidant group present in vegetable oils (Fernandes et al., 2013). The $\gamma$-tocotrienol isomer was observed as a major GSO constituent. In relation to this content, it can be seen that cold pressed oils had a concentration that was 2 times higher when compared to the legislation (Food and Agriculture Organization of the United Nations, 2001). This correspond to more than $96 \%$ of total isomers, with concentrations in the range between 57.22 and $453.48 \mathrm{mg} 100 \mathrm{~g} \mathrm{~g}^{-1}$. In contrast, tocopherol concentrations ( $\alpha$ - and $\gamma$-T) represented less than $1 \%$ of the total from cold pressed samples (Table 1 ). 
Our finds showed close values from Brazilian GSO to other grape seed oils (Fernandes et al., 2013; Madawala et al., 2012; Crews et al., 2006). In this context, $\gamma$-tocotrienol activity has received great attention due to its anti-inflammatory effects, acting on the NF-kB signaling pathway, confirming the functional effect of these compounds (Kaileh \& Sen, 2010) and the inhibition of oxidative stress in HepG2 cells (Choi et al., 2010).

There are several minor compounds present in vegetable oils, including fat-soluble vitamins, phytosterols, pigments and phenolic compounds. Some of them had significant antioxidant capacity, which means greater potential to inhibit lipid oxidation reactions to which oils are more susceptible, i.e. the presence of minor constituents contributes to product quality and nutritional value improvements. There are numerous studies reporting minor compound concentrations in GSO produced in many countries, such as Portugal, Spain, Italy and France (Fernandes et al., 2013; Navas, 2009; Rubio et al., 2009; Crews et al., 2006). Similarly, it was important to characterize GSO from the Brazilian market as no data were found in the literature.

Our results showed a great variability of minor compound concentrations, which may be related to the different production area to obtain the Brazilian GSO products. As the cold pressing process does not involve chemical or heat treatment, this stands out as an interesting method once consumers prefer, currently, natural and healthy products, and especially those which maintain, integrally or otherwise, the bioactive compounds present in seeds (Passos et al., 2010).

There is a significant loss of many compounds, particularly phenolic acids, during oil extraction due to the low solubility in the lipophilic phase, however some has potential to migrate during extraction; as a result, turbidity can be found. In this sense, Table 3 shows low luminance value $\left(L^{*}\right)$ for the samples, which indicate high turbidity. The total phenolics quantification in the present study was in agreement with the results of different studies in the literature (Siger et al., 2008).

Color evaluation in commercial products is important, not only as an attribute that contributes to consumer acceptance, but also because of its relationship with the bioactive compounds present. Data from CieLab coordinates showed a predominance of component $\mathrm{b}^{\star}$ (yellow) and component $\mathrm{a}^{*}$ (green). These results indicate a yellowish color, which is characteristic of vegetable oils. No data were found regarding GSO color in the literature; nevertheless the results obtained from palm, soybean, sunflower, olive, corn and pumpkin cold pressed oils ranged from 44.8 to 69.5 for the parameter $L^{*}$, with negative values for parameter $\mathrm{a}^{*}$ (range from 0.2 to 4.4 ) and parameter $\mathrm{b}^{*}$ (range from 9.2 to 28.8 ) (Rezig et al., 2012).

Volatile compounds were obtained, suggesting that compounds such as hexanol and isoamyl alcohol resulted from the seed fermentation process, indicating an herbaceous and fruity note, respectively. Aldehydes such as pentanal, hexanal and furfural, fruity and/or floral notes, as well as ethyl hexanoate and ethyl octanoate esters were presented in the samples. On the other hand, it should be noted that during the oxidation process, some volatile compounds are formed which impart an unpleasant flavor, as observed by the identification of isovaleric acid, styrene and 2-heptenal from cold pressed URS, OOV and CAC samples. Cavalli et al. (2004) demonstrated that during the extraction process, maturation stage and cultivation practices can deeply influence the volatile compounds profile of oils.

In order to characterize the potential antioxidant activity present in commercial GSO and due to the complexity of interactions and diverse mechanisms found in many antioxidant compounds present in vegetable oils, three different methods were used. As TEAC method is based on electron transfer from an antioxidant compound to an oxidant, this method do not show significant correlation with ORAC, hydrophilic and lipophilic assays, whereas for these other two methods they are based on hydrogen atom transfer of an antioxidant compound to block the peroxyl radical. On the other hand, because of the similarity between the TEAC methodology and the determination of total phenolic compounds, we found a strong and significant correlation between the two methods $(\mathrm{r}=0.791 ; p<0.05)$. Meanwhile, antioxidant capacity identified by the hydrophilic and lipophilic assays were compared with the ORAC method and the hydrophilic method gave results that were higher than the lipophilic method, showing that after extraction, antioxidant compound selection occurs. Our suggestion is that in the hydrophilic method, from the hydrophilic GSO extract, the selection of water-soluble compounds occurs, such as phenolic derivatives of benzoic acid (gallic acid) and/or alcoholic derivatives (flavonoids, secoiroids, lignans). On the other hand, in the lipophilic GSO extract, major contributors to antioxidant activity are namely carotenoids ( $\beta$-carotene, lutein), tocopherols and tocotrienols, chlorophylls, polymeric proanthocyanidines and high molecular weight tannins (Leão et al., 2014).

In general, high antioxidant activity was found; this outstanding activity could be attributed to the high phytochemical content, as they are rich in phenolics, carotenoids and tocopherols (see Tables 1 and 2). However, during the extraction process, regardless of the possibility of the significant loss of many of these minor compounds, due to their low solubility in oil, a strong positive correlation was found between the lipophilic ORAC method values and the content of compounds which have a greater affinity to non-polar components such as carotenoids $(\mathrm{r}=0.792$, $p<0.05)$, vitamin E activity $(\mathrm{r}=0.860, p<0.01), \gamma$-T3 $(\mathrm{r}=0.81$; $p<0.05)$ and total phytosterols $(\mathrm{r}=0.910, p<0.01)$, as well as with their fractions campesterol, $\beta$-sitosterol and stigmasterol $(\mathrm{r}=0.909, \mathrm{r}=0.908$ and $\mathrm{r}=0.887, p<0.01$, respectively).

Antioxidant activity determination by the TEAC method showed that samples had activities ranging from 53.41 to $205.52 \mu \mathrm{M}$ TE $100 \mathrm{~g}^{-1}$. Bail et al. (2008) investigated Austrian GSO antioxidant capacity (from 9.0 to $116.0 \mu \mathrm{M} \mathrm{TE} 100 \mathrm{~g}^{-1}$ of oil) and Fernandes et al. (2013) worked with ten different oils from many varieties of Portuguese grapes, founding a range from 33.4 to $48.9 \mathrm{mmol}$ TE $100 \mathrm{~mL}^{-1}$ of oil.

Total phenolic content showed high, positive and significant correlation with carotenoids content $(\mathrm{r}=0.756, p<0.05)$, component $\mathrm{b}^{*}(\mathrm{r}=0.934, p<0.01)$, tocopherol content $(\mathrm{r}=0.822$, $p<0.05)$ and hydrophilic antioxidant activity when using the ORAC method $(\mathrm{r}=0.831, p<0.05)$. 
In summary, our results indicate GSO obtained from Brazilian markets showed presence of important minor components (such as phenolics, carotenoids, $\gamma$-tocotrienol and $\beta$-sitosterol) and linoleic essential fatty acid, which leads GSO to be recognized as an interesting ingredient for human consumption.

It is widely known that vegetable oils consumption in place of solid fats is vital important to maintaining for health maintenance. In particular, this context, grape seed oil stands out as a suitable alternative to other commonly used vegetable oils because of its once contains high amounts of $n-6$ fatty acid and bioactive compounds and equally importantly, it is an environmentally friendly oil as it is a sustainable option for agro-industrial to obtain a value added a by-product of wine and grape juice-making processes.

\section{Conclusions}

Agro-industrial waste is an excellent way of adding value to crop production. In this context, the wine processing industry produces tons of seeds as by-products. According to our analysis, grape seed oils are rich in essential and other health-benefitting fatty acids. In particular, Brazilian grape seed oil contains a higher number of volatiles, and from the nutritional aspect, high amount of total antioxidant capacity and total phenols. Our results demonstrate the viability of developing nutraceuticals or functional food ingredients from these commercial cold pressed grape seed oils for optimal human health.

\section{Acknowledgements}

The authors are grateful for financial support of CAPES (Coordenação de Aperfeiçoamento de Pessoal de Nível Superior) for the Doctoral scholarship to Fernanda B. Shinagawa and Fernanda C. de Santana and CNPq (559768/2010-9) for the project funding.

\section{References}

American Oil Chemists' Society - AOCS. (2009). Official methods and recommended practices (6th ed.). Champaign: AOCS.

Bail, S., Stuebiger, G., Krist, S., Unterweger, H., \& Buchbauer, G. (2008). Characterization of various grape seed oils by volatile compounds, triacylglycerol composition, total phenols and antioxidant capacity. Food Chemistry, 108, 1122-1132. PMid:26065780. http://dx.doi. org/10.1016/j.foodchem.2007.11.063.

Cavalli, J. F., Fernandez, X., Lizzani-Cuvelier, L., \& Loiseau, A. M. (2004). Characterization of volatile compounds of French and Spanish virgin olive oils by HS-SPME: Identification of qualityfreshness markers. Food Chemistry, 88(1), 151-157. http://dx.doi. org/10.1016/j.foodchem.2004.04.003.

Choi, Y., Lee, J., Kim, Y., Yoon, J., Jeong, H. S., \& Lee, J. (2010). A Tocotrienol-Rich Fraction from grape seeds inhibits oxidative stress induced by tert-Butyl Hydroperoxide in HepG2 cells. Journal of Medicinal Food, 13(5), 1240-1246. PMid:20726785. http://dx.doi. org/10.1089/jmf.2009.1342.

Crews, C., Hough, P., Godward, J., Brereton, P., Lees, M., Guiet, S., \& Winkelmann, W. (2006). Quantitation of the main constituents of some authentic grape-seed oils of different origin. Journal of Agricultural and Food Chemistry, 54(17), 6261-6265. PMid:16910717. http://dx.doi.org/10.1021/jf060338y.
Dhvamani, S., Rao, Y. P. C., \& Lokesh, B. R. (2014). Total antioxidant activity of selected vegetable oils and their influence on total antioxidant values in vivo: a photochemiluminescence based analysis. Food Chemistry, 164, 551-555. PMid:24996369. http:// dx.doi.org/10.1016/j.foodchem.2014.05.064.

Duchateau, G. S. M. J. E., Bauer-Plank, C. G., Louter, A. J. H., van der Ham, M., Boerma, J. A., van Rooijen, J. J. M., \& Zandbelt, P. A. (2002). Fast and accurate method for total 4-desmethyl sterol(s) content in spreads, fat-blends, and raw materials. Journal of the American Oil Chemists' Society, 79(3), 273-278. http://dx.doi.org/10.1007/ s11746-002-0473-y.

Fernandes, L., Casal, S., Cruz, R., Pereira, J. A., \& Ramalhosa, E. (2013). Seed oils of ten traditional Portuguese grape varieties with interesting chemical and antioxidant properties. Food Research International, 50(1), 161-166. http://dx.doi.org/10.1016/j.foodres.2012.09.039.

Food and Agriculture Organization of the United Nations - FAO. (2001). Codex standard for named vegetable oils: Codex STAN 2101999. Rome: FAO.

Food and Agriculture Organization of the United Nations - FAO. (2014). FAOSTAT. Retrieved from http://faostat3.fao.org.

Hills, W. E., \& Swain, T. (1959). The phenolic constituents of Punnus domestica. The quantitative analysis of phenolic constituents. Journal of the Science of Food and Agriculture, 19, 63-68.

Instituto Brasileiro de Geografia e Estatística - IBGE. (2012). Produção Agrícola Municipal. Retrieved from ftp://ftp.ibge.gov.br/ Producao_Agricola

Kaileh, M., \& Sen, R. (2010). Role of NF- $\kappa B$ in the anti-inflammatory effects of tocotrienols. Journal of the American College of Nutrition, 29(3, Suppl), 334S-339S. PMid:20823493. http://dx.doi.org/10.108 0/07315724.2010.10719848.

Kim, Y., Choi, Y., Ham, H., Jeong, H. S., \& Lee, J. (2013). Protective effects of oligomeric and polymeric procyanidin fractions from defatted grape seed on tert-butyl hydroperoxide-induced oxidative damage in HepG2 cells. Food Chemistry, 137(1-4), 136-141. PMid:23200001. http://dx.doi.org/10.1016/j.foodchem.2012.10.006.

Laakso, P. (2005). Analysis of sterol from various food matrices. European Journal of Lipid Science and Technology, 107(6), 402-410. http://dx.doi.org/10.1002/ejlt.200501134.

Leão, K. M. M., Sampaio, K. L., Pagani, A. A. C., \& da Silva, M. A. A. P. (2014). Odor potency, aroma profile and volatiles composition of cold pressedoil from industrial passion fruit residues. Industrial Crops and Products, 58, 280-286. http://dx.doi.org/10.1016/j. indcrop.2014.04.032.

Madawala, S. R. P., Kochhar, S. P., \& Dutta, P. C. (2012). Lipid components and oxidative status of selected specialty oils. Grasas y Aceites, 63, 143-151. http://dx.doi.org/10.3989/gya.083811.

Minguez-Mosquera, M. I., Rejano-Navarro, L., Gandul-Rojas, B., Gomez, A. H. S., \& Garrido-Fernandez, J. (1991). Color-pigment correlation in virgin olive oil. Journal of the American Oil Chemists' Society, 68(5), 332-336. http://dx.doi.org/10.1007/BF02657688.

Nakamura, Y., Tsuji, S., \& Tonogai, Y. (2003). Analysis of proanthocyanidins in grape seed extracts, health foods and grape seed oils. Journal of Health Science, 49(1), 45-54. http://dx.doi.org/10.1248/jhs.49.45.

Navas, P. B. (2009). Chemical composition of the virgin oil obtained by mechanical pressing form several grape seed varieties (Vitis vinífera L.) with emphasis on minor constituents. Archivos Latinoamericanos de Nutricion, 59(2), 214-219. PMid:19719020.

Passos, C. P., Silva, R. M., da Silva, F. A., Coimbra, M. A., \& Silva, C. M. (2010). Supercritical fluid extraction of grape seed (Vitis vinifera L.) oil. Effect of the operating conditions upon oil composition and 
antioxidant capacity. Chemical Engineering Journal, 160(2), 634-640. http://dx.doi.org/10.1016/j.cej.2010.03.087.

Prior, R. L., Hoang, H., Gu, L., Wu, X., Bacchiocca, M., Howard, L., Hampsch-Woodill, M., Huang, D., Ou, B., \& Jacob, R. (2003). Assays for hydrophilic and lipophilic antioxidant capacity (oxygen radical absorbance capacity (ORACFL)) of plasma and other biological and food samples. Journal of Agricultural and Food Chemistry, 51(11), 3273-3279. PMid:12744654. http://dx.doi.org/10.1021/jf0262256.

Ranjith, A., Sarin-Kumar, K., Venugopalan, V. V., Arumughan, C., Sawhney, R. C., \& Singh, V. (2006). Fatty acids, tocols, and carotenoids in pulp oil of three sea buckthorn species (Hippophae rhamnoides, $\mathrm{H}$. salicifolia, and H. tibetana) grown in the Indian Himalayas. Journal of the American Oil Chemists' Society, 83(4), 359-364. http://dx.doi. org/10.1007/s11746-006-1213-z.

Re, R., Pellegrini, N., Proteggente, A., Pannala, A., Yang, M., \& RiceEvans, C. (1999). Antioxidant Activity Applying an Improved ABTS radical cation decolorization assay. Free Radical Biology \& Medicine, 26(9-10), 1231-1237. PMid:10381194. http://dx.doi.org/10.1016/ S0891-5849(98)00315-3.
Rezig, L., Chouaibi, M., Msaada, K., \& Hamdi, S. (2012). Chemical composition and profile characterisation of pumpkin (Cucurbita maxima) seed oil. Industrial Crops and Products, 37(1), 82-87. http:// dx.doi.org/10.1016/j.indcrop.2011.12.004.

Rockenbach, I. I., Rodrigues, E., Gonzaga, L. V. \& Fett, R. (2010). Fatty acid composition of grape (Vitis vinifera L. and Vitis labrusca L.) seed oil. Brazilian Journal of Food Technology, III SSA, 23-26.

Rubio, M., Alvarez-Ortí, M., Alvarruiz, A., Fernandéz, E., \& Pardo, J. E. (2009). Characterization of oil obtained from grape seeds collected during Berry development. Journal of Agricultural and Food Chemistry, 57(7), 2812-2815. PMid:19256538. http://dx.doi. org/10.1021/jf803627t.

Sabir, A., Unver, A., \& Kara, Z. (2012). The fatty acid and tocopherol constituents of the seed oil extracted from 21 grape varieties (Vitis spp.). Journal of the Science of Food and Agriculture, 92(9), 1982-1987. PMid:22271548. http://dx.doi.org/10.1002/jsfa.5571.

Siger, A., Nogala-Kalucka, M., \& Lampart-Szczapa, E. (2008). The content and antioxidant activity of phenolic compounds in coldpressed plant oils. Journal of Food Lipids, 15(2), 137-149. http:// dx.doi.org/10.1111/j.1745-4522.2007.00107.x. 